\title{
Can Prosthetic Hands Mimic a Healthy Human Hand?
}

\author{
Ka Ho Ng ${ }^{1,+}$, Vaheh Nazari ${ }^{2,+}$ and Monzurul Alam ${ }^{1, *(\mathbb{D}}$ \\ 1 Department of Biomedical Engineering, The Hong Kong Polytechnic University, Hong Kong 999077, China; \\ ka-ho-anson.ng@connect.polyu.hk \\ 2 Faculty of Medical Sciences and Technologies, Islamic Azad University-Science and Research Branch, \\ Tehran, Iran; vahe_nazari@yahoo.com \\ * Correspondence: md.malam@connect.polyu.hk; Tel.: +852-6213-5054 \\ + Authors contributed equally.
}

Citation: Ng, K.H.; Nazari, V.; Alam, M. Can Prosthetic Hands Mimic a Healthy Human Hand? Prosthesis 2021, 3, 11-23. https:// doi.org/10.3390/prosthesis3010003

Received: 23 December 2020

Accepted: 25 January 2021

Published: 28 January 2021

Publisher's Note: MDPI stays neutral with regard to jurisdictional claims in published maps and institutional affiliations.

Copyright: (c) 2021 by the authors. Licensee MDPI, Basel, Switzerland. This article is an open access article distributed under the terms and conditions of the Creative Commons Attribution (CC BY) license (https:/ / creativecommons.org/licenses/by/ $4.0 /)$.

\begin{abstract}
Historical evidence suggests that prostheses have been used since ancient Egyptian times. Prostheses were usually utilized for function and cosmetic appearances. Nowadays, with the advancement of technology, prostheses such as artificial hands can not only improve functional, but have psychological advantages as well and, therefore, can significantly enhance an individual's standard of living. Combined with advanced science, a prosthesis is not only a simple mechanical device, but also an aesthetic, engineering and medical marvel. Prosthetic limbs are the best tools to help amputees reintegrate into society. In this article, we discuss the background and advancement of prosthetic hands with their working principles and possible future implications. We also leave with an open question to the readers whether prosthetic hands could ever mimic and replace our biological hands.
\end{abstract}

Keywords: hand prostheses; amputation; bionics; dexterity; neural communication

\section{Introduction}

Prostheses have been in our lives since the ancient times and have made a significant impact in our living [1,2]. They were primarily utilized for function and cosmetic appearance [3]. Today, owing to the advancement of technology, artificial hands can not only improve functional, but also psychological well-being [4].

It is needless to say how important are human hands for performing sophisticated movements and enabling human beings to communicate with their surroundings and do most daily activities like feeding, washing and so forth. Therefore, it is possible to regain missing functions with a prosthetic limb to enhance the quality of life of the amputee [5]. Although prostheses are able to assist amputees in retrieving the ability of hands, developing an artificial hand capable of mimicking a natural human hand still remains a challenge.

Patients would be able to have intuitive control over the prosthetic device through a broad range of orders. Utilizing the device would guarantees the safety of patients as well as provide a natural appearance. Neural activity-based prosthesis could be more intuitive and natural since they would be user-centered [6]. However, commonly used prosthetic hands utilize surface electromyography (sEMG) signals from the residual muscles to control them [7].

Although commercial myoelectric prostheses can simulate many human gestures with help from microprocessors, they commonly lack sensory feedback. Without sensory feedback, myoelectric prosthesis users do not have the tactile sense they need to control their prostheses [8]. Hence, the control is done by visual feedback. These days, providing wearable artificial limbs with advanced tactile perceptions and artificial skins, and facilitating dexterous exploration and interaction with the environment, remains challenging. To bridge the technological gap between artificial and biological skin, several efforts have 
been made recently [9]. To have the beneficial effect of capturing touch and acquiring realtime tactile information, an electronic skin (e-skin) can be applied onto the prosthesis [10]. Comprehensive somatosensory feedback can be transmitted from the prosthesis to the user, which thereby closes the loop in a myoelectric artificial limb.

The ultimate aim is to construct an artificial extremity that can evoke conscious sensation and execute sophisticated motor functions. A common limitation that the majority of the prostheses share is that they are open-loop systems, lacking proprioceptive feedback which thereby affects the full functionality of the natural limb or organ [11]. There have been several attempts, with variable and minimal success, to provide feedback. Newer techniques include sensory regenerative peripheral nerve interfaces, targeted sensory reinnervation, engineered neural interfaces and optogenetics [12]. Via feedback, these methods will dramatically pave the way for more intuitive prosthetic control.

\section{Current Prosthetic Hands}

Reinhold Reiter created the first actively controlled therapeutic myoelectric prosthesis (Figure 1) in the early 1940s [13]. Since then, a variety of prostheses have been developed, but have been restricted by cost, weight and unattractive appearance, which caused them to be unacceptable in the mainstream [14]. Global design efforts strive for innovative developments in 3D-printed prosthetic devices with practical and psychological impacts. Their main concern to meet social and cultural needs, however, has restricted the designers' ability to address the demands of the global community [15].

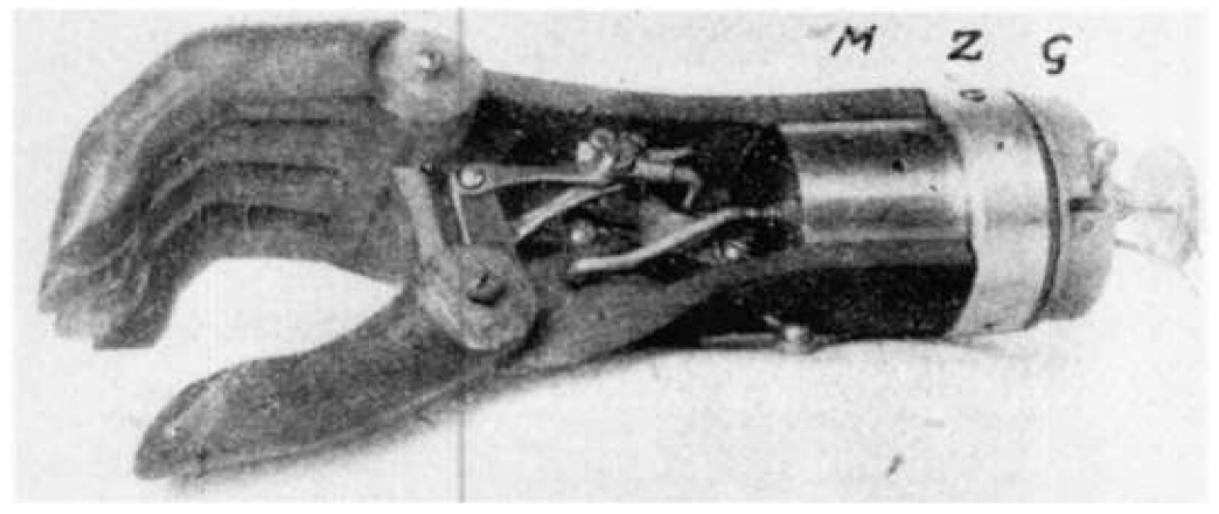

Figure 1. Photograph of the first electric powered myoelectric prosthetic hand used by the inventor Reinhold Reiter (Circa 1943). Reprinted with permission from [13].

Some wide initiatives on dexterity and intelligent prosthetics were launched with the rise of bio-mechatronics technology. These designs include bebionics generated by Ottobock (Leeds, United Kingdom), LUKE/DEKA Arm (Salt Lake, UT, USA), CyberHand (Pisa, Italy), SmartHand (Lund, Sweden and Pisa, Italy) and Neurobotics (Seattle, WA, USA). Ottobock, for instance, developed a multidegree of freedom robotic hand called bebionic 3 (Figure 2), controlled with a force myography (FMG) sensing technique. With 14 different grip styles and hand configurations, this robot helps patients perform activities of daily living (ADL), such as fixing shoelaces, holding luggage, opening doors, eating, flipping on lights, texting and more [16].

A16 degrees of freedom (DOF) SmartHand prosthesis was created by the ARTS Lab at Scuola Superiore Sant'Anna, Pisa, Italy [17]. The delivery of prosthesis actuation based on four DC motors and tendon transmission helps the hand to execute core grasping tasks useful in everyday living activities (Figure 3) [18]. The artificial hand is fitted with a customized palm-embedded control architecture to move its actuators in multiple control modes and share proprioceptive and exteroceptive sensory inputs from the external world. The hand fingers typically contain 32 locations, force and tactile sensors, all of which are obtained from the local controller and are capable of providing input to patients through suitable interfaces. 

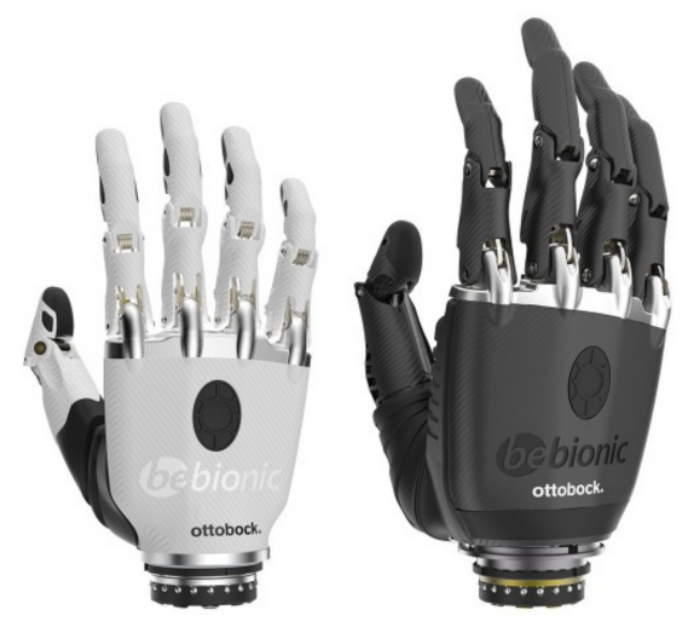

Figure 2. Bebionic 3 robotic hand developed by Ottobock (Photo courtesy from Otto Bock HealthCare LP, 11501 Alterra Parkway Suite 600, Austin, TX 78758, USA).

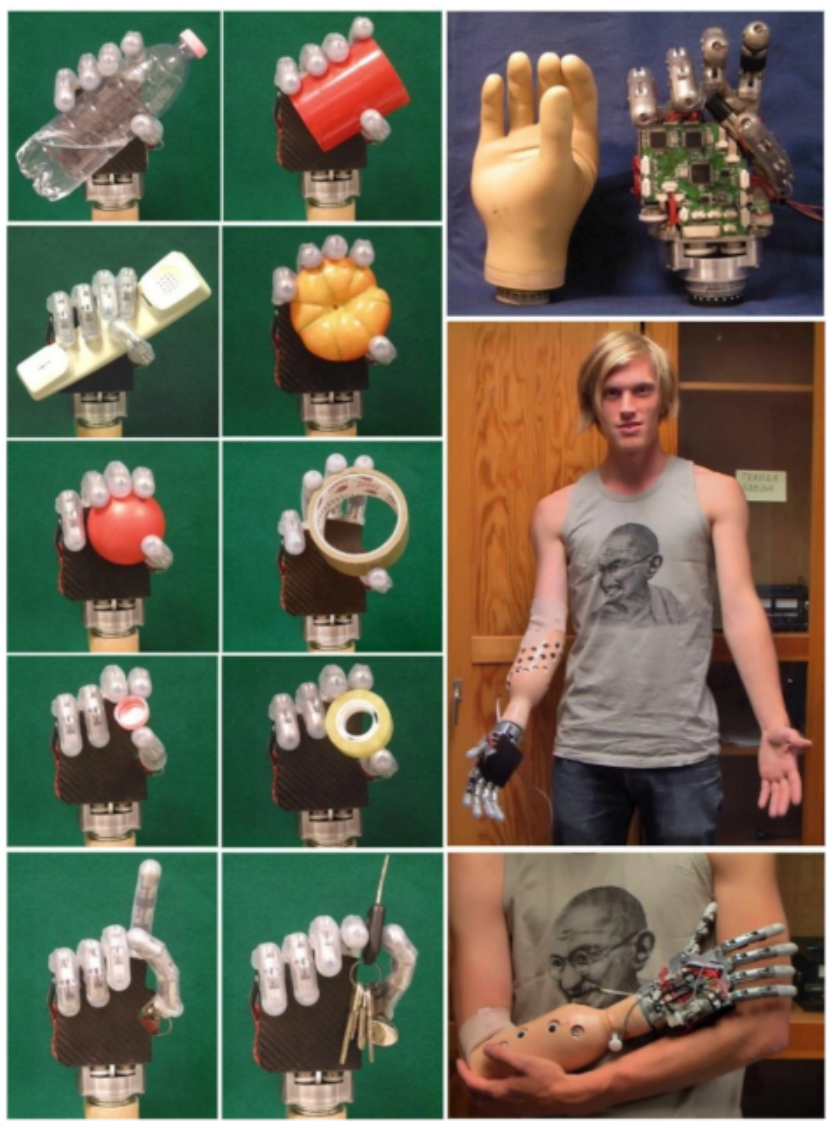

Figure 3. Functional grasping and outlook of the SmartHand developed by the ARTS Lab at Scuola Superiore Sant'Anna, Pisa, Italy. Reprinted with permission from [18].

Revolutionizing Prosthetics (Figure 4) is a DARPA (Arlington, VA, USA)-funded project that develops neurally-integrated upper limb prostheses which can be controlled by the patients using neural pathways [19]. Applied physical laboratory (APL), Baltimore, MD, USA, of the Johns Hopkins University is leading the project. Their prosthesis is a mixture of sensors, actuators, neuroscience and complex software with the goal of creating a novel prosthesis [20]. Despite their serious injuries, the modular prosthetic limbs allow upper extremity amputees to perform ADL [21,22]. 

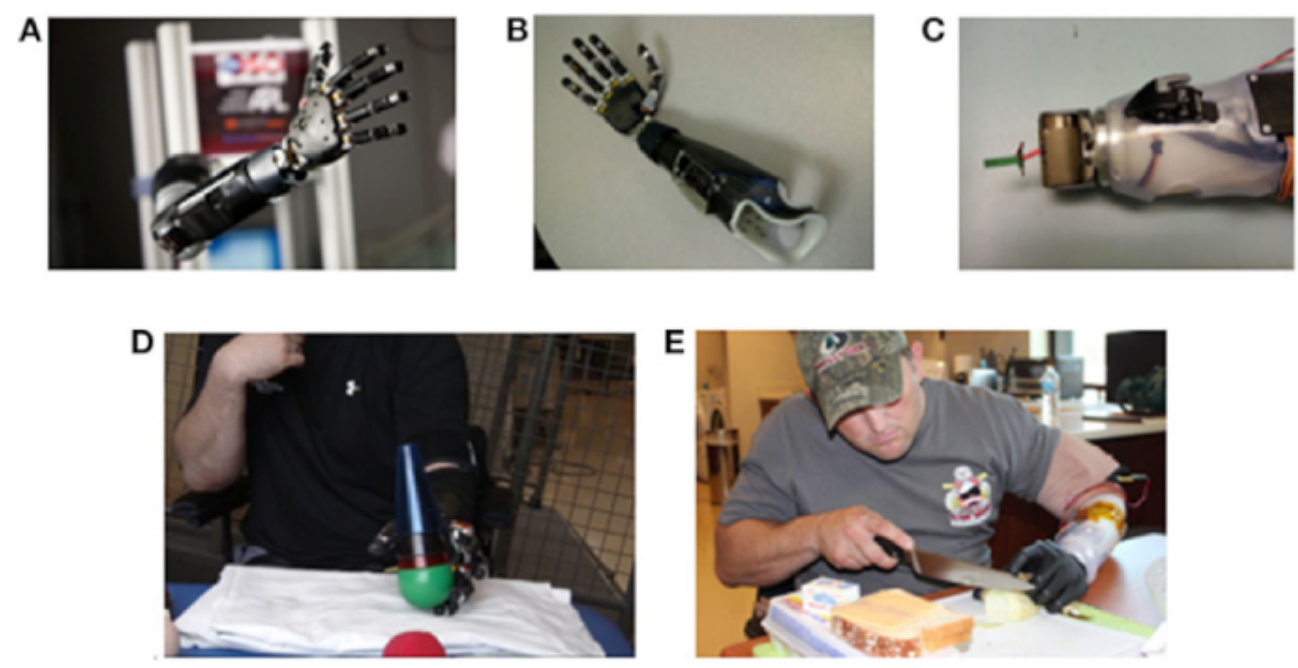

Figure 4. (A-C) Different components and configuration of the Modular Prosthetic Limb (MPL), built by Johns Hopkins University's Applied Physics Laboratory, Baltimore, MD, USA. (D,E) An amputee performing reaching, grasping, manipulation and cooking tasks using the MPL. Reprinted with permission from [23].

The University of Utah has also developed a prototype arm called LUKE (Figure 5), which has the ability to interact with the nerves of the amputee and introduce touch into prosthesis through the use of advanced interfaces between the machine and body [24]. The Utah group spent hours studying 200 to 300 implanted electrodes into the nerves, and 32 electrodes implanted into individual muscles, to map the muscles' and nerves' roles in upper arm movement and feeling.

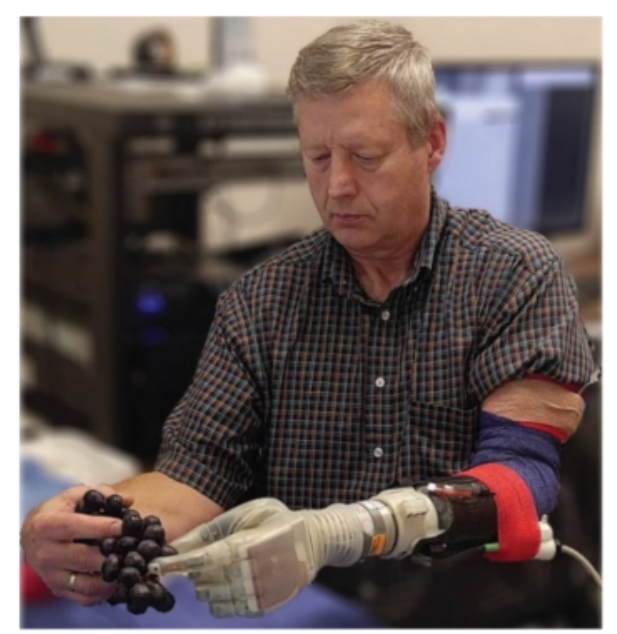

Figure 5. Plucking a grape by using the LUKE arm without smashing it is a process that would be incredibly challenging without tactile feeling. (Photo courtesy from the Center for Neural Interfaces, University of Utah, Salt Lake, UT, USA).

There have been many prosthetic hands developed in recent years with different functionalities, all of which aim towards a single objective-to mimic complex hand functions. Table 1 summarizes different features and components of a number of recently developed prosthetic hands. 
Table 1. Specification of prosthetic hands.

\begin{tabular}{|c|c|c|c|c|c|c|c|}
\hline Name & $\begin{array}{c}\text { Type of } \\
\text { Prosthesis }\end{array}$ & DOF & $\begin{array}{l}\text { Type of } \\
\text { Control }\end{array}$ & Controller & $\begin{array}{l}\text { Number of } \\
\text { Actuators }\end{array}$ & Weight (g) & Cost (US \$) \\
\hline Bebionic 3 & Forearm & 6 & FMG/EMG & $\mathrm{N} / \mathrm{A}$ & 5 & $433-616$ & 35,000 \\
\hline $\begin{array}{l}\text { Revolutionizing } \\
\text { Prosthetics V } 1.0\end{array}$ & Upper arm & 17 & $\mathrm{~N} / \mathrm{A}$ & $\mathrm{N} / \mathrm{A}$ & 17 & $\mathrm{~N} / \mathrm{A}$ & $\mathrm{N} / \mathrm{A}$ \\
\hline $\begin{array}{l}\text { Revolutionizing } \\
\text { Prosthetics V } 2.0\end{array}$ & Upper arm & 22 & $\mathrm{~N} / \mathrm{A}$ & $\mathrm{N} / \mathrm{A}$ & 22 & $\mathrm{~N} / \mathrm{A}$ & N/A \\
\hline SmartHand & Forearm & 16 & $\mathrm{~N} / \mathrm{A}$ & $\begin{array}{c}\text { High-level hand controller } \\
\text { (HLHC, based on Microchip } \\
\text { microcontroller) }\end{array}$ & 4 & 570 & $\mathrm{~N} / \mathrm{A}$ \\
\hline LUKE & Forearm & 6 & EMG & $\mathrm{N} / \mathrm{A}$ & 6 & 1270 & 100,000 \\
\hline ADA Hand & Forearm & 5 & NM & Arduino & 5 & 380 & $\mathrm{~N} / \mathrm{A}$ \\
\hline Andrianesis' hand & Forearm & 15 & EMG & Microcontroller & 9 & 350 & $\mathrm{~N} / \mathrm{A}$ \\
\hline Gretsch' HAND & Forearm & 10 & EMG & Arduino Micro & 5 & 240 & $300 \mathrm{M}$ \\
\hline O'Neill's HAND & Forearm & 15 & EMG & $\mathrm{N} / \mathrm{A}$ & 5 & 960 & $500 \mathrm{M}$ \\
\hline Brunel hand 1.0 & Forearm & 9 & $\mathrm{~N} / \mathrm{A}$ & Arduino & 4 & 371 & $\mathrm{~N} / \mathrm{A}$ \\
\hline Brunel hand 2.0 & Forearm & 9 & $\mathrm{~N} / \mathrm{A}$ & Arduino & 4 & 332 & 1634 \\
\hline MERO Hand & Forearm & 2 & $\mathrm{~N} / \mathrm{A}$ & Arduino UNO & 2 & 336 & $\mathrm{~N} / \mathrm{A}$ \\
\hline Touch Hand II & Forearm & $\mathrm{N} / \mathrm{A}$ & EMG & $\begin{array}{c}\text { Microcontroller } \\
\text { (MCU (MK20DX256 32bit ATM } \\
\text { Cortex-M4)) }\end{array}$ & 6 & 451 & 1052 \\
\hline Dextrus & Forearm & 6 & EMG & $\mathrm{N} / \mathrm{A}$ & 6 & 450 & $1000 \mathrm{M}$ \\
\hline Ariyanto's Hand & Forearm & 5 & $\mathrm{NM}(\mathrm{N} / \mathrm{A})$ & Arduino Nano & 5 & 261 & $\mathrm{~N} / \mathrm{A}$ \\
\hline $\begin{array}{l}\text { Hackberry Bionic } \\
\text { Hand }\end{array}$ & Forearm & $\mathrm{N} / \mathrm{A}$ & EMG/EEG & Arduino Micro & 3 & $\mathrm{~N} / \mathrm{A}$ & 372 \\
\hline i-Limb & Forearm & 6 & EMG & $\mathrm{N} / \mathrm{A}$ & 5 & $460-615$ & 60,000 \\
\hline Hanson Arm & Upper arm & 7 & $\begin{array}{l}\text { EEG and } \\
\text { EOG }\end{array}$ & $\mathrm{N} / \mathrm{A}$ & 7 & $\mathrm{~N} / \mathrm{A}$ & 7150 \\
\hline Canizares' Hand & Forearm & 5 & EMG & Arduino Nano & 5 & 682 & $\mathrm{~N} / \mathrm{A}$ \\
\hline Bebionic Hand & Forearm & 6 & EMG & $\mathrm{N} / \mathrm{A}$ & 5 & $495-539$ & 11,000 \\
\hline Michelangelo & Forearm & 2 & EMG & Host PC & 2 & 600 & 75,000 \\
\hline MANUS-HAND & Forearm & $\mathrm{N} / \mathrm{A}$ & EMG & Microcontroller (PIC17C756) & 9 & 400 & $\mathrm{~N} / \mathrm{A}$ \\
\hline Rehand & Forearm & $\mathrm{N} / \mathrm{A}$ & $\begin{array}{l}\text { distance } \\
\text { sensor }\end{array}$ & Arduino pro mini & 1 & 467 & 1250 \\
\hline $\begin{array}{l}\text { KIT prosthetic } \\
\text { hand }\end{array}$ & Forearm & 10 & $\begin{array}{l}\text { embedded } \\
\text { vision } \\
\text { system }\end{array}$ & $\begin{array}{c}\text { ARM Cortex M7 processor } \\
\text { (STM32F7 series, STMicroelectronics) }\end{array}$ & 2 & $\mathrm{~N} / \mathrm{A}$ & 1214 \\
\hline X-Limb & Forearm & 13 & EMG & $\begin{array}{c}\text { Microcontroller (Atmel 8-bit } \\
\text { ATmega2560, Chandler, AZ, USA ) }\end{array}$ & 5 & 253 & 200 \\
\hline
\end{tabular}

N/A: not available and M: cost of material.

\section{Conventional Socketed Myoelectric Prosthetic Hand Action}

Under generality and safety issues, most of the prosthetic companies tend to produce noninvasive myoelectric prosthetic hands. The most common technique to operate the artificial hand is capturing surface EMG. EMG signals can be obtained on the remaining part of the arm without any implantation or invasion [25]. As EMG does not require installation by surgery, it is comparably at low risk and has higher acceptance by the amputees.

Generally, two or three electrodes are attached to the prosthetic socket for the activity of the prosthetic hand, leading to the capture of the electromyography (EMG) signal from the electrical actions of the excitable muscle cells. The EMG signal is then amplified $(1000 \times)$ and bandpass filtered $(20-500 \mathrm{~Hz})$ by an analog amplifier before sampling at $1 \mathrm{khz}$ [26]. The digitized EMG signal is further processed online for detecting the user's intent. Commonly used EMG envelope detection steps are show in Figure 6. The microprocessor of the myoelectric arm then drives the motors of the arm/hand joint to complete 
the various and dexterous actions based on the detected signals. Therefore, the myoelectric prosthesis can achieve the aim of the human-computer interface.

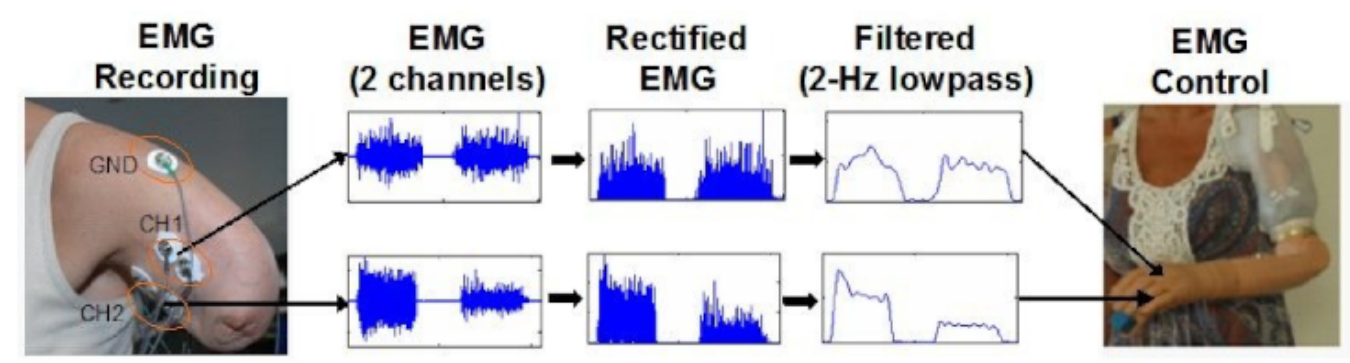

Figure 6. A simple control strategy of an upper-limb myoelectric prosthesis by using surface electromyogram (EMG) signal. Reprinted with permission from [27].

However, due to the no-invasive process, these kinds of commercial myoelectric prosthetic arms lack the capability of a real human arm. Since the electrodes are sensitive to the surface action potentials, changes in electrode-skin impedance and electrode dislocation affect the signal quality [28]. In other words, due to the superficial EMG signal and the concern of signal feature, they cannot receive noiseless signals. Noise arises from sweating, location of electrodes or noise from other muscles affecting the performance. In addition, users cannot manipulate their joint movement in a sophisticated way and are required to receive a great deal of training. Furthermore, these prostheses cannot provide the users with bionic tactile feedback. Therefore, many researchers aim to study the neuromusculoskeletal arm which can directly and successfully capture the signal information from the nerve or muscle [28,29].

\section{Futuristic Prosthetic Hand}

Somatosensory stimuli are integral components of our sensorimotor behaviors such as touch and proprioception. Loss of somatosensory perception limits our ability to control motor function [8]. Due to developments in neural interface technologies and the discoveries of their critical role in improving the functionality of prosthetic limbs for amputees, research into somatosensory neural prostheses has advanced rapidly in recent decades.

Somatosensory information is carried from the periphery to the brain through ascending neural pathways in an intact nervous system. The lack of somatosensory inputs is an interruption in the neuronal pathways. Artificial sensors must be designed to acquire the interactive variables of the prosthesis to restore lost sensory function, and a neural interface must be created to deliver sensory information to the neural system above the interruption level. Tactile input from the fingers proves to be important in prosthetic hands for amputees for gripping functions, as well as for restoring a sense of embodiment of the prosthetic hand $[24,30]$. The difficulty of interfacing with the nervous system, extending from the skin to the peripheral nerve, spinal cord, and cerebral cortex, is addressed by different methods [31]. Based on the particular locations in the ascending neural pathway, various interface technologies have been developed to relay external information. For example, basic mechanical sensation or transcutaneous electrical nerve stimulation through the skin of the body can elicit more simplistic senses corresponding to various types of cutaneous receptors including touch, pressure, buzz, vibration, numbness and tingling sensations. In addition, several kinds of stimulation electrodes can be inserted at different positions in the somatosensory system from peripheral nerves to the cerebral cortex. In the peripheral nervous system, for instance, embedded microelectrode stimulation may elicit flutter-vibration, pain, contact, joint motion, and location in or on peripheral nerves (Figure 7) [32]. 


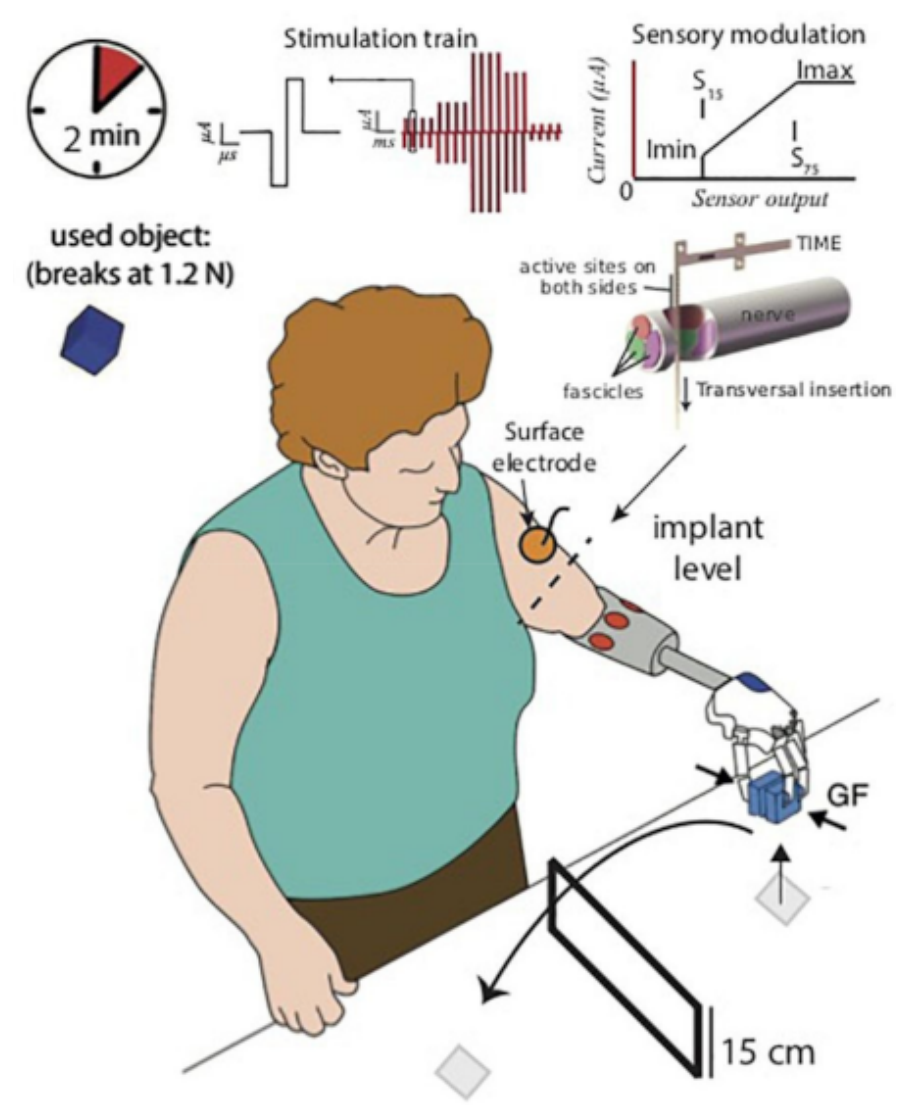

Figure 7. A robotic hand prosthesis powered by surface EMG signals and neural sensory feedback was used by the patient through electrodes implanted in her ulnar nerve. Reprinted with permission from [32].

The new neural interface gives greater access to the sensory fibers in the dorsal root ganglia or in the ascending spinal sensory tracts at the level of the spinal cord. The somatosensory cortex is a direct target in the brain to elicit various forms of sensations such as squeeze, tap, pinch, press, motion, vibration, and goose bumps, in response to particular stimuli at specific areas of the body. It has also been shown that the sense of contact or vibration on individual fingers can be elicited by intracortical microstimulation of the primary somatosensory cortex [33]. Many factors need to be closely balanced for interfacing with the nervous system. This involve the naturalness and accuracy of the details about body parts, sensation modalities, interface stability, level of body invasion, implantation and surgery and, therefore, when applied to these sites for the provision of sensory input, each interface technology should be carefully assessed in relation to these considerations [34].

In 2020, Max Ortiz-Catalan et al. introduced a prosthesis with sensory and motor elements anchored in the bone for patients with transhumeral amputation [34]. Bidirectional interaction between the prosthetic hand and implanted electrodes in the muscles and nerves of the upper arm was made possible by implantation and anchored by osseointegration to the humerus (Figure 8) [34].

In order to detect signals from the patient's voluntary contraction in the remaining muscles, electrodes were inserted into the epimysium of the triceps and the biceps muscles so as to apply motion motors in the prosthetic side. Moreover, they placed a spiral cuff electrode around the ulnar nerve and an additional electrode around the median nerve to acquire sensory feedback. By electrically activating the afferent nerve fibers that had been cut in the amputation, the patients were provided with tactile sensory input by prosthetic sensors. 


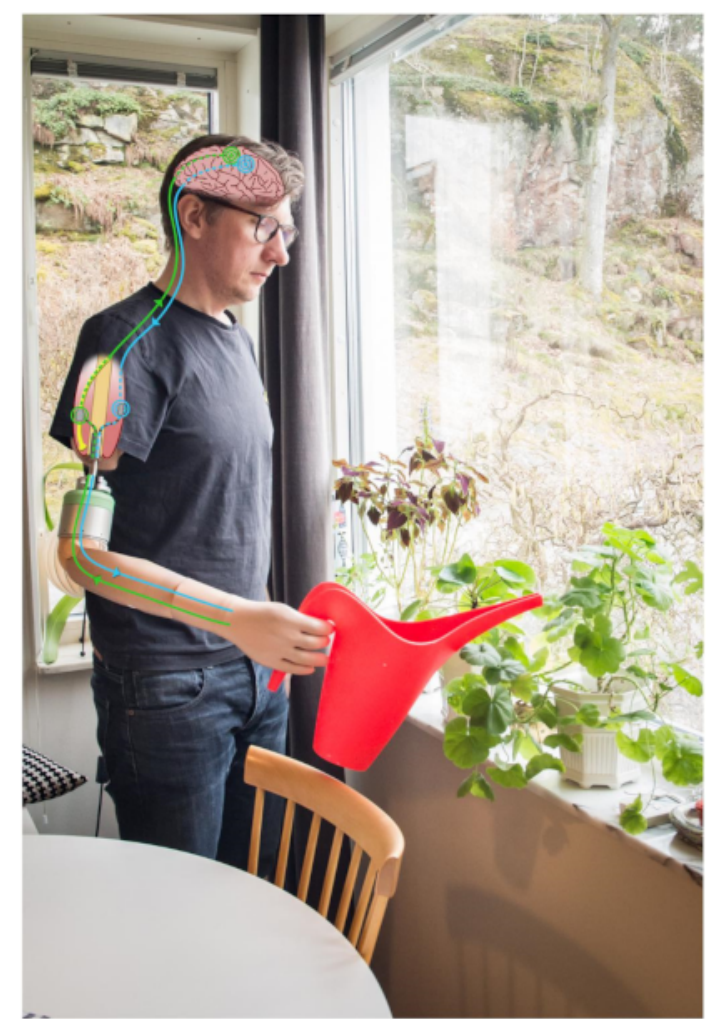

Figure 8. Bidirectional interaction between the prosthetic hand and implanted electrodes was made possible by implantation. Reprinted with permission from [34].

With the use of a titanium screw gets inserted between the bone (the fixture) and the abutment, prosthetic limbs may be anchored in the bone at the amputation stump. The new central screw and abutment screw can be made up of feed-through connectors that allow wired electrical contact from inside to outside the body. To evaluate the functionality of the electrodes and the communication interface, the impedance of the electrodes can be monitored over-time.

Myoelectric activities of users were successfully recorded on the reinnervated muscles and increased in amplitude over-time [35]. At an early stage of applying the prostheses, patients were merely able to sense difference with over $50 \%$ increased or decreased frequency of stimulation. After a month of daily use of sensory feedback, it was observed that approximately $30 \%$ in the frequency of stimulation could be sensed as an increase or decrease in the difference of tactile sensation. Additionally, the electrode impedance increased for around five months after implantation, then remained relatively stable. After synchronization, patients documented beneficial impacts on their self-esteem, self-image and social relationships. Also, this self-contained neuromusculoskeletal arm prosthesis could relieve phantom limb pain.

\section{3D Printed Prosthetic Hand}

Slow, unavailable, and prohibitively costly (ranging from a few to ten thousand dollars) are common features of conventional methods of producing prostheses [36]. With an added degree of flexibility and personalization, which are not traditionally used, the advancement of 3D printing technology allows prostheses to be manufactured costeffectively [37]. 3D printing technology opens up new possibilities for its application in prosthetics. With the assistance of computer-aided design (CAD) techniques, it is possible to design and modify individual prosthetic devices very easily [38].

$3 \mathrm{D}$ printing technology is attractive for rapid prototyping, and the components designed with this technology can be used as finished products. A number of open-source platforms, or start-ups, are working on the use of 3D printers in prosthesis development, 
particularly upper limb prostheses. These include HACKberry, KIT prosthetic hand, ADA hand, Brunel hand, OpenBionics and cyborg beast. Figure 9 shows some of these 3D printed prosthetic hands. There are several advantages of incorporating 3D printing technology in the production of artificial limbs, as prostheses require a highly individualized and versatile design approach and, if possible, low maintenance requirements and cost limitation [39]. In addition, for the 3D prosthetic hand, multiple control mechanisms are being incorporated to create a product with comparable features to the more advanced hands on the market, while at the same time ensuring that the hand remains cheaper than those currently available [40].

A

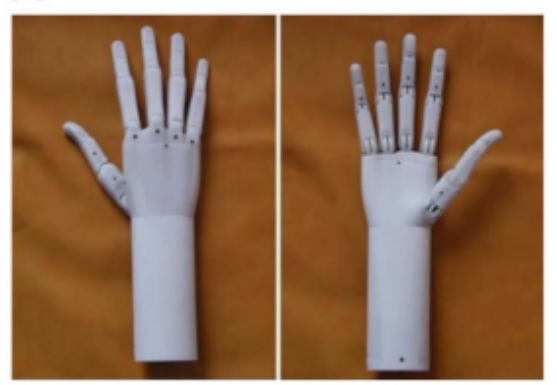

C

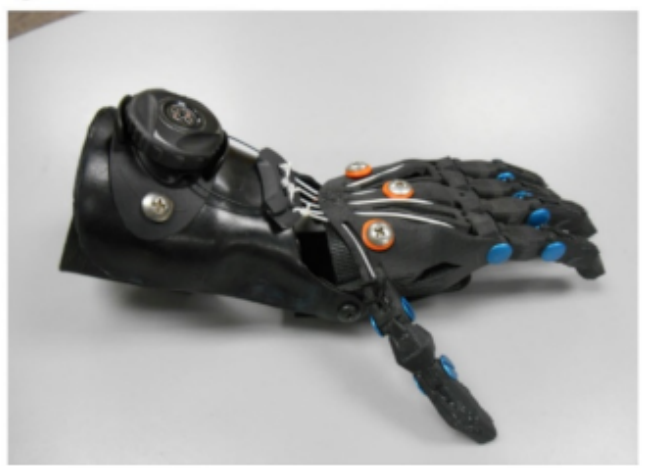

B

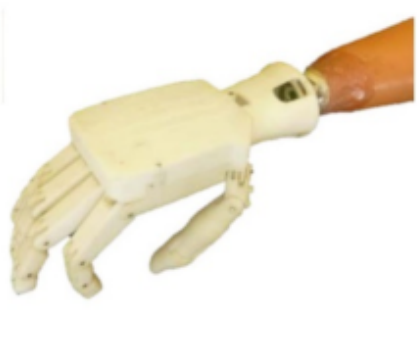

D

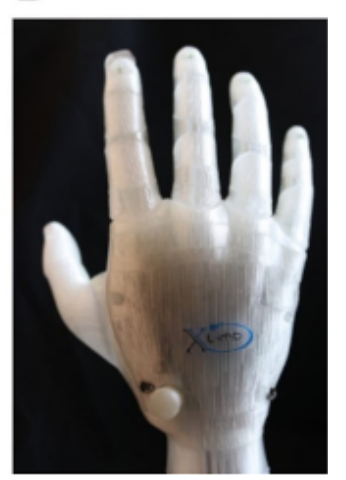

Figure 9. 3D printed hand prosthesis. (A) Andrianesis' Hand, (B) Touch hand II, (C) Cyborg beast and (D) X-Limb. Reprinted with permission from [37,40,41].

Unfortunately, through 3D printing alone, it is not yet feasible to get prostheses with the same degree of consistency as commercial ones. However, the manufacturing of materials and 3D printing technology appear to be similar to the standard of the design of traditional production forms [38].

\section{Artificial Muscles}

Due to motors and signal processors, myoelectric prosthetic limbs are usually heavy and difficult to control swiftly. Kanik et al. developed fiber based artificial muscles to increase performance and minimize the weight of the prosthetic limbs [42]. These actuators are controlled thermally and optically and have the ability to extend over 1000 percent of their length and lift 650 times heavier objects. These fibers were constituted by cyclic olefin copolymer elastomer (COCe) as well as high-density polyethylene (PE) blocks (25 mm by $8 \mathrm{~mm}$ cross-section, $200 \mathrm{~mm}$ long) and were covered by poly methyl methacrylate (PMMA) (Figure 10). 


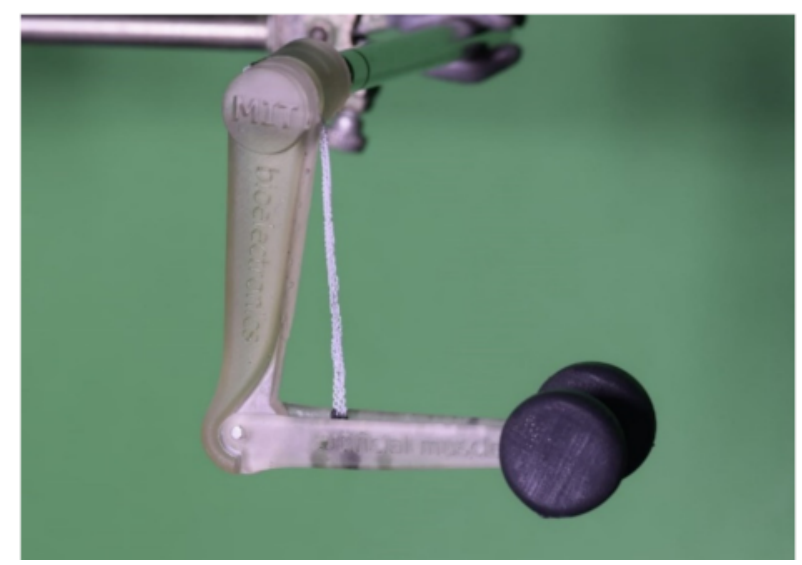

Figure 10. Miniature arm with bundled of fiber-based muscles formed by PE and COCe. (Photo courtesy from Mehmet Kanik and Sirma Orguc, Massachusetts Institute of Technology, Cambridge, MA, USA).

An experiment was carried out in which a single fiber muscle was able to raise a dumbbell of $1 \mathrm{~g}$ once the muscle was stimulated by a heat gun $\left(10^{\circ} \mathrm{C}\right)$ [42]. During multiple cycles of $2 \mathrm{~s}$, with heat pulses divided by $6 \mathrm{~s}$ recesses during which the fiber muscle cooled down to room temperature for $6 \mathrm{~s}$, this activity was reversible and repeatable. For temperature gradients above $50^{\circ} \mathrm{C}$, persistent deformation was observed.

\section{Discussion and Conclusions}

Over the last century, the production of prosthetic hands has come a long way. Currently, bionic hand prostheses have been established that are suitable for patients and robust, secure and convenient with improved functionality [43]. However, these prostheses also need to resolve major difficulties in order to mimic, or even progress, on the inherent side. Progress in the fields of biomedical engineering, robotics and artificial intelligence (AI) has provided a glimpse of hope for millions of amputees, and it is possible that there will be commercially accessible artificial limbs in the near future that have both feeling and precise motor coordination. Using AI in the branches of orthosis and prosthesis is in the primary stage and not widely applied. The bulk of AI projects have been used in prototypes that have not been marketed yet [44].

Techniques of prosthesis regulation can be found as adaptations to initial neural pathways. Imperfect recovery and unsolid cognitive knowledge should be augmented by other technological means to recover the missed information in the damaged neuromuscular system, when a great deal of data are lost in the affected region [45]. Neural signals from the central/peripheral nervous system (PNS/CNS) including, mechanomyography-MMG, EMG, electroneurography-ENG, electroencephalography-EEG, force myography-FMG and electrocorticography-ECoG, are obtained to recover missing data to allow hand gestures and dexterous movement of the prosthesis [46-48]. Out of the signals mentioned above, sEMG is considered to be the only biological signal currently accepted for medicinal applications and is distinguished by its low cost and noninvasive acquisition [46].

At present, there are several different methods of developing and manufacturing a prosthesis for the upper limbs. It is important to classify the techniques of managing a prosthesis into two categories: noninvasive and invasive [49]. The correlation of intracortical signals with the stimulation of the forearm muscles or nerves is an interesting example of an invasive technique. On the other hand, certain noninvasive concepts use electroencephalography (EEG) and electrooculographic (EOG), or a hybrid system, to operate and monitor the prosthesis. These principles are impressive, but they are scientifically challenging and are related to high costs and require a higher degree of learning effort for the user. Therefore, they are not suitable for every patient [50]. 
There have been several methods for controlling noninvasive prostheses, primarily by EMG or EEG signals. Additionally, in recent years, researchers have made significant attempts to utilize new technologies and to propose a new technique such as augmented reality (AR) glasses [51], inductive tongue control system (ITCS) [52], mechanomyography (MMG), voice commands and inertial measurement units (IMUs) to control prosthetic hands $[49,53]$. Some ideas, however, have demonstrated that even simplistic methods can deliver persuasive outcomes. Body-powered prostheses, e-Nable and Cyborg beast, for example, are very cost-effective and allow the patient to grip an object by rotating a portion of the body such as the shoulder or wrist [50].

The ultimate aim is to advance a prosthetic hand with sensory feedback, which is capable of closely imitating the real hand. High degrees of freedom in cutting-edge robotic arms resemble the fine flexibility of the hands [54]. Myoelectric prosthetic limbs are normally weighty and difficult to easily monitor because of the motors and signal processors. To reduce the weight of the prosthetic limbs and increase durability, artificial muscles have been introduced that can accelerate the evolution of robotic artificial limbs. Progresses in actuators based on polymers have created unparalleled capabilities, but the manufacture of these instruments with tunable measurements on a large scale remains a challenge [19]. The loss of sensation, however, remains the key limit to returning the normal limb's maximum functionality. There have been many advancements towards a prosthetic device with progressive tactile input to the user with variable and restricted success, delivering dense, dispersed sensing of the tactile contact between the prosthesis and the environment, and transmitting this knowledge to the user through high-density electrotactile stimulation, allowing intuitive hand control [54,55].

Based on the world health organization (WHO) report on disabilities, there are more than 30 million people with amputations living in poor countries, $80 \%$ of whom cannot afford commercial prosthetic hands. Producing prostheses with a 3D printer can be costeffective and it is possible to design and produce customized and individualized prostheses. This can be one of the best alternatives for low-income patients.

Author Contributions: Conceptualization, K.H.N. and M.A.; writing-original draft preparation, K.H.N. and V.N.; writing-review and editing, V.N. and M.A.; supervision, M.A.; funding acquisition, M.A. All authors have read and agreed to the published version of the manuscript.

Funding: This study was partially supported by the Hong Kong Polytechnic University (UAKB).

Institutional Review Board Statement: Not applicable.

Informed Consent Statement: Not applicable.

Data Availability Statement: Not applicable.

Conflicts of Interest: Authors declare no conflict of interests.

\section{References}

1. Alam, M.; He, J. Lower-Limb Neuroprostheses: Restoring Walking after Spinal Cord Injury. In Emerging Theory and Practice in Neuroprosthetics; Ganesh, R.N., Yina, G., Eds.; IGI Global: Hershey, PA, USA, 2014; pp. 153-180.

2. Das, N.; Nagpal, N.; Bankura, S.S. A review on the advancements in the field of upper limb prosthesis. J. Med. Eng. Technol. 2018, 42, 532-545. [CrossRef] [PubMed]

3. Thurston, A. Paré and prosthetics: The early history of artificial limbs. ANZ J. Surg. 2007, 77, 1114-1119. [CrossRef] [PubMed]

4. Desmond, D.; MacLachlan, M. Psychological issues in prosthetic and orthotic practice: A 25 year review of psychol-ogy in Prosthetics and Orthotics International. Prosthet. Orthot. Int. 2002, 26, 182-188. [CrossRef] [PubMed]

5. Cordella, F.; Ciancio, A.L.; Sacchetti, R.; Davalli, A.; Cutti, A.G.; Guglielmelli, E.; Zollo, L. Literature Review on Needs of Upper Limb Prosthesis Users. Front. Neurosci. 2016, 10, 209. [CrossRef] [PubMed]

6. Li, Y.; Alam, M.; Guo, S.; Ting, K.H.; He, J. Electronic bypass of spinal lesions: Activation of lower motor neurons directly driven by cortical neural sig-nals. J. Neuroeng. Rehabil. 2014, 11, 107. [CrossRef] [PubMed]

7. Kumar, D.K.; Jelfs, B.; Sui, X.; Arjunan, S.P. Prosthetic hand control: A multidisciplinary review to identify strengths, shortcomings, and the future. Biomed. Signal Process. Control. 2019, 53, 101588. [CrossRef]

8. Wijk, U.; Carlsson, I.K.; Antfolk, C.; Björkman, A.; Rosén, B. Sensory Feedback in Hand Prostheses: A Prospective Study of Everyday Use. Front. Neurosci. 2020, 14, 663. [CrossRef] 
9. Yang, J.C.; Mun, J.; Kwon, S.Y.; Park, S.; Bao, Z.; Park, S. Electronic Skin: Recent Progress and Future Prospects for Skin-Attachable Devices for Health Monitor-ing, Robotics, and Prosthetics. Adv. Mater. 2019, 31, 1904765. [CrossRef]

10. Núñez, C.G.; Manjakkal, L.; Dahiya, R. Energy autonomous electronic skin. npj Flex. Electron. 2019, 3, 1-24. [CrossRef]

11. Peh, W.Y.X.; Raczkowska, M.; Teh, Y.; Alam, M.; Thakor, N.V.; Yen, S.-C. Closed-loop stimulation of the pelvic nerve for optimal micturition. J. Neural Eng. 2018, 15, 066009. [CrossRef]

12. Yildiz, K.A.; Shin, A.Y.; Kaufman, K.R. Interfaces with the peripheral nervous system for the control of a neuro-prosthetic limb: A review. J. Neuroeng. Rehabil. 2020, 17, 43. [CrossRef] [PubMed]

13. Childress, D.S. Historical aspects of powered limb prostheses. Clin. Prosthet. Orthot. 1985, 9, 2-13.

14. Zuo, K.J.; Olson, J.L. The evolution of functional hand replacement: From iron prostheses to hand transplantation. Plast. Surg. 2014, 22, 44-51. [CrossRef]

15. Arabian, A.; Varotsis, D.; McDonnell, C.; Meeks, E. Global social acceptance of prosthetic devices. In 2016 IEEE Global Humanitarian Technology Conference (GHTC); IEEE: Seattle, WA, USA, 2016; pp. 563-568.

16. Ahmadizadeh, C.; Merhi, L.-K.; Pousett, B.; Sangha, S.; Menon, C. Toward Intuitive Prosthetic Control: Solving Common Issues Using Force Myography, Surface Electromyography, and Pattern Recognition in a Pilot Case Study. IEEE Robot. Autom. Mag. 2017, 24, 102-111. [CrossRef]

17. Cipriani, C.; Controzzi, M.; Carrozza, M.C. Objectives, criteria and methods for the design of the SmartHand transradial prosthesis. Robotica 2009, 28, 919-927. [CrossRef]

18. Cipriani, C.; Controzzi, M.; Carrozza, M.C. The SmartHand transradial prosthesis. J. Neuroeng. Rehabil. 2011, 8, 29. [CrossRef] [PubMed]

19. Bridges, M.; Beaty, J.; Tenore, F.; Para, M.; Mashner, M.; Aggarwal, V.; Acharya, S.; Singhal, G.; Thakor, N. Revolutionizing Prosthetics 2009: Dexterous Control of an Upper-Limb Neuroprosthesis. Johns Hopkins APL Tech. Dig. 2010, 28, $210-211$.

20. Lake, C.; Miguelez, J.M. Evolution of microprocessor based control systems in upper extremity prosthetics. Technol. Disabil. 2003, 15, 63-71. [CrossRef]

21. Collinger, J.L.; Wodlinger, B.; Downey, J.E.; Wang, W.; Tyler-Kabara, E.C.; Weber, D.J.; McMorland, A.J.C.; Velliste, M.; Boninger, M.L.; Schwartz, A.B. High-performance neuroprosthetic control by an individual with tetraplegia. Lancet 2013, 381, 557-564. [CrossRef]

22. Johannes, M.S.; Faulring, E.L.; Katyal, K.D.; Para, M.P.; Helder, J.B.; Makhlin, A.; Moyer, T.; Wahl, D.; Solberg, J.; Clark, S.; et al. Chapter 21-The Modular Prosthetic Limb. In Wearable Robotics; Rosen, J., Ferguson, P.W., Eds.; Academic Press: London, UK, 2020; pp. 393-444.

23. Perry, B.N.; Moran, C.W.; Armiger, R.S.; Pasquina, P.F.; Vandersea, J.W.; Tsao, J.W. Initial Clinical Evaluation of the Modular Prosthetic Limb. Front. Neurol. 2018, 9, 153. [CrossRef]

24. George, J.A.; Kluger, D.T.; Davis, T.S.; Wendelken, S.M.; Okorokova, E.V.; He, Q.; Duncan, C.C.; Hutchinson, D.T.; Thumser, Z.C.; Beckler, D.T.; et al. Biomimetic sensory feedback through peripheral nerve stimulation improves dexterous use of a bionic hand. Sci. Robot. 2019, 4, eaax2352. [CrossRef] [PubMed]

25. Sudarsan, S.; Sekaran, E.C. Design and Development of EMG Controlled Prosthetics Limb. Procedia Eng. 2012, 38, 3547-3551. [CrossRef]

26. Phinyomark, A.; Khushaba, R.N.; Scheme, E. Feature Extraction and Selection for Myoelectric Control Based on Wearable EMG Sensors. Sensors 2018, 18, 1615. [CrossRef] [PubMed]

27. Li, G. Electromyography Pattern-Recognition-Based Control of Powered Multifunctional Upper-Limb Prostheses. Adv. Appl. Electromyogr. 2011, 6, 99-116.

28. Farina, D.; Jiang, N.; Rehbaum, H.; Holobar, A.; Graimann, B.; Dietl, H.; Aszmann, O.C. The Extraction of Neural Information from the Surface EMG for the Control of Upper-Limb Prostheses: Emerging Avenues and Challenges. IEEE Trans. Neural Syst. Rehabil. Eng. 2014, 22, 797-809. [CrossRef]

29. Memberg, W.D.; Stage, T.G.; Kirsch, R.F. A fully implanted intramuscular bipolar myoelectric signal recording elec-trode. Neuromodulation 2014, 17, 794-799. [CrossRef]

30. Weber, D.J.; Hao, M.; Urbin, M.A.; Schoenewald, C.; Lan, N. Sensory information feedback for neural prostheses. In Biomedical Information Technology; Academic Press: London, UK, 2020; pp. 687-715.

31. Micera, S.; Rossini, P.M.; Rigosa, J.; Citi, L.; Carpaneto, J.; Raspopovic, S.; Tombini, M.; Cipriani, C.; Assenza, G.; Carrozza, M.C.; et al. Decoding of grasping information from neural signals recorded using peripheral intrafascicular inter-faces. J. Neuroeng. Rehabil. 2011, 8, 53. [CrossRef]

32. Valle, G.; D'Anna, E.; Strauss, I.; Clemente, F.; Granata, G.; Di Iorio, R.; Controzzi, M.; Stieglitz, T.; Rossini, P.M.; Petrini, F.M.; et al. Hand Control With Invasive Feedback Is Not Impaired by Increased Cognitive Load. Front. Bioeng. Biotechnol. 2020, 8. [CrossRef]

33. Alam, M.; Rodrigues, W.; Pham, B.N.; Thakor, N.V. Brain-machine interface facilitated neurorehabilitation via spinal stimulation after spinal cord injury: Recent progress and future perspectives. Brain Res. 2016, 1646, 25-33. [CrossRef]

34. Middleton, A.; Ortiz-Catalan, M. Neuromusculoskeletal Arm Prostheses: Personal and Social Implications of Living with an Intimately Integrated Bionic Arm. Front. Neurorobot. 2020, 14, 39. [CrossRef]

35. Ortiz-Catalan, M.; Mastinu, E.; Sassu, P.; Aszmann, O.; Brånemark, R. Self-Contained Neuromusculoskeletal Arm Prostheses. N. Engl. J. Med. 2020, 382, 1732-1738. [CrossRef] 
36. Koprnicky, J.; Šafka, J.; Ackermann, M. Using of 3D Printing Technology in Low Cost Prosthetics. Mater. Sci. Forum 2018, 919, 199-206. [CrossRef]

37. Zuniga, J.M.; Katsavelis, D.; Peck, J.; Stollberg, J.; Petrykowski, M.; Carson, A.; Fernandez, C. Cyborg beast: A low-cost 3d-printed prosthetic hand for children with upper-limb differences. BMC Res. Notes 2015, 8, 1-9. [CrossRef]

38. Koprnický, J.; Najman, P.; Šafka, J. 3D printed bionic prosthetic hands. In 2017 IEEE International Workshop of Electronics, Control, Measurement, Signals and Their Application to Mechatronics (ECMSM); IEEE: Donostia-San Sebastian, Spain, 2017 ; pp. 1-6.

39. Oppus, C.M.; Prado, J.R.R.; Escobar, J.C.; Marinas, J.A.G.; Reyes, R.S. Brain-computer interface and voice-controlled 3D printed prosthetic hand. In 2016 IEEE Region 10 Conference (TENCON); IEEE: Singapore, 2017; pp. 2689-2693.

40. Mohammadi, A.; Lavranos, J.; Zhou, H.; Mutlu, R.; Alici, G.; Tan, Y.; Choong, P.; Oetomo, D. A practical 3D-printed soft robotic prosthetic hand with multi-articulating capabilities. PLOS ONE 2020, 15, e0232766. [CrossRef]

41. Jones, G.; Stopforth, R. Mechanical Design and Development of the Touch Hand II Prosthetic Hand. R D J. S. Afr. Inst. Mech. Eng. 2016, 32, 23-24.

42. Kanik, M.; Orguc, S.; Varnavides, G.; Kim, J.; Benavides, T.; Gonzalez, D.; Akintilo, T.; Tasan, C.C.; Chandrakasan, A.P.; Fink, Y.; et al. Strain-programmable fiber-based artificial muscle. Science 2019, 365, 145-150.

43. Clement, R.G.; Bugler, K.E.; Oliver, C.W. Bionic prosthetic hands: A review of present technology and future aspira-tions. Surgeon 2011, 9, 336-340. [CrossRef]

44. Nayak, S.; Das, R.K. Application of Artificial Intelligence (AI) in Prosthetic and Orthotic Rehabilitation. In Service Robotics; IntechOpen: London, UK, 2020; pp. 1-23.

45. Yang, D.; Liu, H. Human-machine shared control: New avenue to dexterous prosthetic hand manipulation. Sci. China Ser. E Technol. Sci. 2020, 1-7. [CrossRef]

46. Fang, Y.; Hettiarachchi, N.; Zhou, D.; Liu, H. Multi-Modal Sensing Techniques for Interfacing Hand Prostheses: A Review. IEEE Sens. J. 2015, 15, 6065-6076. [CrossRef]

47. Ahmed, R.U.; Alam, M.; Zheng, Y.-P. Experimental spinal cord injury and behavioral tests in laboratory rats. Heliyon 2019, 5, e01324. [CrossRef]

48. Alam, M.; Zheng, Y.-P. Motor neuroprosthesis for injured spinal cord: Who is an ideal candidate? Neural Regen. Res. 2017, 12, 1809-1810. [CrossRef] [PubMed]

49. Otte, A. Invasive Versus Non-Invasive Neuroprosthetics of the Upper Limb: Which Way to Go? Prosthesis 2020, 2, 237-239. [CrossRef]

50. Baron, J.; Hazubski, S.; Otte, A. 3D Multi-Material Printing of an Anthropomorphic, Personalized Replacement Hand for Use in Neuroprosthetics Using 3D Scanning and Computer-Aided Design: First Proof-of-Technical-Concept Study. Prosthesis 2020, 2, 362-370. [CrossRef]

51. Hazubski, S.; Hoppe, H.; Otte, A. Non-contact visual control of personalized hand prostheses/exoskeletons by tracking using augmented reality glasses. 3D Print. Med. 2020, 6, 1-3. [CrossRef]

52. Johansen, D.; Cipriani, C.; Popovic, D.B.; Struijk, L.N.S.A. Control of a Robotic Hand Using a Tongue Control System-A Prosthesis Application. IEEE Trans. Biomed. Eng. 2016, 63, 1368-1376. [CrossRef]

53. Fonseca, L.; Tigra, W.; Navarro, B.; Guiraud, D.; Fattal, C.; Bó, A.; Fachin-Martins, E.; Leynaert, V.; Gélis, A.; Azevedo-Coste, C. Assisted Grasping in Individuals with Tetraplegia: Improving Control through Residual Muscle Con-traction and Movement. Sensors 2019, 19, 4532. [CrossRef]

54. Nghiem, B.T.; Sando, I.C.; Gillespie, R.B.; McLaughlin, B.L.; Gerling, G.J.; Langhals, N.B.; Urbanchek, M.G.; Cederna, P.S. Providing a Sense of Touch to Prosthetic Hands. Plast. Reconstr. Surg. 2015, 135, 1652-1663. [CrossRef]

55. Seminara, L.; Franceschi, M.; Pinna, L.; Ibrahim, A.; Valle, M.; Dosen, S.; Farina, D. Electronic skin and electrocutaneous stimulation to restore the sense of touch in hand prosthetics. In 2017 IEEE International Symposium on Circuits and Systems (ISCAS); IEEE: Baltimore, MD, USA, 2017; pp. 1-4. 